\title{
Bioconversión de glicerol a dihidroxiacetona usando un proceso fed- batch mediante fermentación con Gluconobacter oxydans
}

\author{
Bioconversion of Glycerol to Dihydroxyacetone Using a Fed-Batch by a \\ Fermentation Process with Gluconobacter Oxydans
}

\author{
De Avila-Montiel Gezira \\ Universidad de Cartagena \\ Facultad de ingeniería \\ Correo:gdeavilam@unicartagena.edu.co \\ Realpe-Jiménez Álvaro \\ Universidad de Cartagena \\ Facultad de ingeniería \\ Correo:arealpe@unicartagena.edu.co \\ Duran-Ariza Jhon Edward \\ Universidad de Cartagena \\ Facultad de ingeniería \\ Correo:Jhon_edaoo@hotmail.com
}

\author{
Acevedo-Morantes María \\ Universidad de Cartagena \\ Facultad de ingeniería \\ Correo:macevedom@unicartagena.edu.co \\ Bonfante-Álvarez Heidy Yaneth \\ Universidad de Cartagena \\ Facultad de ingeniería \\ Correo:hybonfantea@gmail.com
}

Información del artículo: recibido: junio de 2015, reevaluado: julio de 2015, aceptado: febrero de 2016

\section{Resumen}

La conversión de glicerol a dihidroxiacetona (DHA) se realizó mediante un proceso fed-batch, con concentraciones de glicerol de 50 y $100 \mathrm{~g} / \mathrm{l}$, utilizando la bacteria Gluconobacter oxydans. La fermentación se realizó durante 72 h, un $\mathrm{pH}$ de 5.3 y una temperatura de $30^{\circ} \mathrm{C}$, bajo un flujo de aireación de $1.66 \mathrm{vvm}$. La cantidad de DHA producida y el glicerol consumido se determinaron aplicando cromatografía de gases y espectrofotometría UV-VIS. Se obtuvo un rendimiento producto/sustrato de $91 \%$ para una concentración de glicerol de $50 \mathrm{~g} / \mathrm{l}$ y $79 \%$ para una concentración de glicerol $100 \mathrm{~g} / \mathrm{l}$. Estos números demuestran que el fenómeno de inhibición se da a altas concentraciones de sustrato y también se observó un menor crecimiento de biomasa. Estos hallazgos demuestran que es viable la producción de dihidroxiacetona a partir de glicerol a un bajo costo, además de solucionar el importante problema de acumulación y contaminación, que el glicerol representa en la producción industrial de biodiesel.

\section{Descriptores:}

- biodiesel

- glicerol

- Gluconobacter oxydans

- dihidroxiacetona

- fed-batch 


\begin{abstract}
The objective of this work was the convertion of glycerol to dihydroxyacetone (DHA) by a fed-batch process at different glycerol concentrations, 50 and $100 \mathrm{~g} / \mathrm{l}$, using Gluconobacter oxydans. The fermentation was conducted during $72 \mathrm{~h}$, at a $\mathrm{pH} 5.3$ and $30^{\circ} \mathrm{C}$ under a flow of 1.66 vom aeration. The amounts of produced DHA and consumed glycerol, were determined using gas chromatography and UV-VIS spectrophotometry. Product-substrate yields were obtained to $91 \%$ and $79 \%$ for concentrations of glycerol $50 \mathrm{~g} / \mathrm{l}$ and $100 \mathrm{~g} / \mathrm{l}$, respectively, which showed the inhibition phenomenon to high substrate concentrations and reduced biomass growth. This research shows that the production of dihydroxyacetone from glycerol is feasible and inexpensive Therefore, it is possible to solve, future problems about pollution and accumulation of glycerol.
\end{abstract}

\section{Introducción}

En la actualidad se buscan combustibles renovables que reemplacen a los combustibles fósiles que se agotan rápidamente, los cuales afectan la economía y son el principal promotor de la contaminación ambiental. Una alternativa sostenible es la producción de biodiesel, un combustible amigable con el ambiente. Las estadísticas de producción de biodiesel en Colombia reflejan una capacidad de producción total de 581 mil toneladas al año, con una producción para el año 2013 de 503337 T/año, presentando un crecimiento anual de 2.8\% (Hancock, 2005; Hederich, 2010). De igual forma, en México la demanda estimada de biodiesel se proyecta para el año 2014 en 80 millones de barriles por día para la mezcla B-20 (Canales et al., 2006). En el proceso de síntesis de biodiesel se obtiene como subproducto glicerol con una relación de $1 \mathrm{~kg}$ por cada $10 \mathrm{~kg}$ de biodiesel producido; de acuerdo con la producción anual de Colombia esta relación proyecta una cantidad considerable de glicerol, superior a 50333.7 T/año, la cual debe aprovecharse para la elaboración de sustancias químicas valiosas y así disminuir costos en eliminación y disposición de este subproducto (Bendeck, 2010; Cárdenas et al., 2006). Por esta razón, muchos investigadores intentaron la transformación del glicerol a productos con valor agregado mediante diversos procesos catalíticos tales como oxidación selectiva, reformado, hidrogenólisis, deshidratación y esterificación, entre otros (Zhu et al., 2013). Actualmente la producción microbiana de la dihidroxiacetona (DHA) es de gran interés debido al alto precio de la dihidroxiacetona con respecto al glicerol (Bauer et al., 2005; Hekmat et al., 2007).

Del glicerol se pueden obtener productos intermedios, tales como: epiclorhidrina, 1.3-dihidroxiacetona, 1.3-propanodiol, ácido propiónico, polihidroxialcanoatos, eritritol, ácido cítrico, hidrógeno, 2.3-butanodiol, ácido succínico, etanol, ácido 3-hidroxipropiónico y ácido glicérico (Cárdenas et al., 2006). De estos se destaca la dihidroxiacetona (DHA), por ser el componente principal de muchos productos de aplicación en medicina, la industria alimenticia, química y farmacéutica (Gupta et al., 2001). La dihidroxiacetona se obtiene por síntesis química o biotecnológica usando la bacteria Gluconobacter oxydans. Esta ruta se considera como la mejor opción por su bajo costo, mayor selectividad y facilidad de purificación y separación de la dihidroxiacetona (DHA) (Cárdenas et al., 2006). Sin embargo, el crecimiento microbiano presenta problemas de inhibición por sustrato y producto. Numerosas investigaciones se desarrollan para mejorar el rendimiento de DHA y lograr el escalamiento a nivel industrial. Algunos estudios son: manipulación de la actividad metabólica de la bacteria, variación del flujo de aireación (Cardeño et al., 2011), inmovilización de la bacteria (Zhong et al., 2011), selección de un biocatalizador inmovilizado más estable y con menos inhibición para la oxidación de glicerol a DHA (Rock et al., 2014) y modo de alimentación, utilizando cepas mutantes de Gluconobacter oxydans (Ming et al., 2010).

El objetivo de esta investigación consiste en el estudio de la producción de DHA a partir de glicerol mediante transformación con G. oxydans, en un proceso fed-batch. El bioproceso se separó en dos etapas: en primer lugar, se establecen las condiciones de cultivo utilizando un proceso batch para determinar el tiempo de alimentación. En segundo lugar, se opera en un biorreactor semicontinuo en el que se buscaron las condiciones adecuadas para la producción de DHA. En este estudio se muestra que es viable la producción microbiana de dihidroxiacetona controlando el flujo de aireación, tiempo de fermentación y condiciones adecuadas de operación en un sistema fed-batch. Por tanto, es po- 
sible solucionar en un futuro problemas de acumulación y contaminación del glicerol.

\section{Materiales y procedimento experimental}

El microorganismo y los medios de cultivo

Gluconobacter oxydans es una bacteria Gram negativa perteneciente a la familia Acetobacteraceae, aerobio obligado, usa el oxígeno como aceptor de electrones en su metabolismo respiratorio (Hekmat et al., 2007). La cepa G. oxydans se compró a la Colección Española de Cultivos Tipo - Universidad de Valencia, identificada como CECT 360 y se seleccionó por su capacidad oxidativa frente a sustratos como el glicerol. Se conservó a $4^{\circ} \mathrm{C}$ tanto en cajas Petri como en agar inclinado, con repiques bimensuales. Se activó en un medio sólido para bacterias ácido acéticas, rico en fuente de carbono: glucosa, $100 \mathrm{~g}$; extracto de levadura, $10 \mathrm{~g}$; $\mathrm{CaCO}_{3} 20 \mathrm{~g}$ y agar $15 \mathrm{~g}$, disueltos en un litro de agua destilada. Como medio de adaptación se empleó glicerina 20 g/l; extracto de levadura, $10 \mathrm{~g} / \mathrm{l}$ y agar $20 \mathrm{~g} / \mathrm{l}$. En ambos medios el $\mathrm{pH}$ se ajustó a 6.0 con tres días de incubación a $30^{\circ} \mathrm{C}$. El medio de producción se preparó con: glicerol 50 y 100 $\mathrm{g} / \mathrm{l}$, extracto de levadura $2.5 \mathrm{~g} / \mathrm{l}, \mathrm{NH}_{4} \mathrm{SO}_{4} 2 \mathrm{~g} / \mathrm{l}, \mathrm{K}_{2} \mathrm{HPO}_{4}$ $0.11 \mathrm{~g} / \mathrm{l}, \mathrm{KH}_{2} \mathrm{PO}_{4} 0.9 \mathrm{~g} / \mathrm{l}$, sorbitol $10 \mathrm{~g} / \mathrm{l}, \mathrm{CaCl}_{2} 1.5 \mathrm{~g} / \mathrm{l}$ (Cardeño et al., 2011). Se midió el pH inicial hasta alcanzar un valor de $5.3 \pm 0.01$. Todos los medios se esterilizaron en autoclave por 20 minutos a $121^{\circ} \mathrm{C}$.

\section{Preparación del inóculo}

El inóculo se preparó con los reactivos utilizados en el medio de fermentación para un volumen de $40 \mathrm{ml}$ de agua destilada con pH 5.3. Posteriormente se esterilizó en autoclave por 20 minutos. Después se hizo el pasaje celular de la cepa activada y por último se procedió a la incubación en un Shaker (Modelo: IN-666. GEMMY$\mathrm{CO})$, a $30^{\circ} \mathrm{C}$, con $150 \mathrm{rpm}$ de agitación durante $24 \mathrm{~h}$.

\section{Cultivo por lote en matraz Erlenmeyer}

Se realizó en 10 matraces Erlenmeyer con capacidad de $100 \mathrm{ml}$, se utilizó un volumen de $25 \mathrm{ml}$ y un matraz Erlenmeyer de $250 \mathrm{ml}$ con $100 \mathrm{ml}$ de medio de fermentación para hacer peso seco. Antes de inocularlos se ajustó el pH a $5.3 \pm 0.01$ y se esterilizaron a $121^{\circ} \mathrm{C}, 15 \mathrm{~min}$ y a la presión normal. Luego a cada matraz Erlenmeyer se le agregaron $0.8 \mathrm{ml}$ de inóculo (Claret et al., 1992), exceptuando el matraz Erlenmeyer de $250 \mathrm{ml}$, al cual se le agregaron $3.2 \mathrm{ml}$ de inóculo. Posteriormente, se colocaron en el agitador orbital para mantener las condiciones del proceso, temperatura $30^{\circ} \mathrm{C}$ y agitación $150 \mathrm{rpm}$ durante un tiempo de $72 \mathrm{~h}$. La toma de muestras se realizó por duplicado, con un lapso de tiempo de $12 \mathrm{~h}$.

\section{Descripción del equipo}

El reactor aireado donde se realizaron los ensayos se basó en un matraz Erlenmeyer de $1000 \mathrm{ml}$ con desprendimiento lateral para salida de aire y alimentación del medio rico en sustrato, dos reguladores de flujo, uno para el suministro de oxígeno al medio, y otro para la toma de muestras. Una bomba se usó con flujo de oxígeno máximo de $34.2 \mathrm{l} / \mathrm{h}$, con un flujo de oxígeno suministrado de $25.6 \mathrm{l} / \mathrm{h}$. Este reactor se instaló dentro de un Shaker, que garantizó la estabilidad del proceso fermentativo, manteniendo la temperatura constante y una agitación adecuada.

\section{Cultivo fed-batch}

El volumen inicial del cultivo fed-batch fue de $300 \mathrm{ml}$ y se hizo el pasaje celular con un inóculo cultivado durante $24 \mathrm{~h}$. Las condiciones del proceso fermentativo fueron: agitación de $150 \mathrm{rpm}$, flujo de aireación 1.66 vvm, $\mathrm{pH}$ de producción $5.3 \pm 0.01$, temperatura $30^{\circ} \mathrm{C}$ durante 72 horas, y con alimentación constante de 30 $\mathrm{ml}$ del medio hasta alcanzar un volumen final de $450 \mathrm{ml}$ cada 12 horas. Se determinó la cantidad de DHA obtenida en cada experimento por duplicado, estableciendo el rendimiento producto/sustrato (Cardeño et al., 2011).

\section{Métodos analíticos}

El consumo de glicerol y la producción de DHA se analizaron por cromatografía de gases (GC), en el equipo (AGILENT 4890DGC), inicialmente se realizaron las curvas de calibración de glicerol y DHA para concentraciones de 0-100 g/l. Estas curvas y las lecturas del cromatógrafo de gases, proporcionaron los datos del consumo de glicerol y la formación de producto (DHA) (Lijuan et al., 2010).

La biomasa celular en $(\mathrm{g} / \mathrm{l})$ se estimó por densidad óptica a $578 \mathrm{~nm}$ en una celda de $2 \mathrm{ml}$, usando un espectrofotómetro (UV-VIS Scanning Spectrophotometer. Model: Spectro UV-2650. Marca: LABOMED. INC). Con estos datos se generó una curva de calibración de biomasa para la G. oxydans, relacionando la absorbancia con la concentración. La cinética de crecimiento de la bacteria se realizó por el método de peso seco (Hekmat et al., 2003). También, la dihidroxiacetona se determinó por colorimetría en el espectrofotómetro UV-VIS a una longitud de onda de $550 \mathrm{~nm}$, con solución de DNS (3.5 
ácido dinitrosalicílico) (Claret et al., 1992). La presencia de DHA se detectó por el color anaranjado presente en las muestras al reaccionar con la solución de ácido dinitrosalicílico (Priscilla et al., 2009).

La separación de DHA del medio líquido se realizó agregando alcohol etílico al medio líquido, donde se suspendió la dihidroxiacetona en el medio y se separó por centrifugación a $2500 \mathrm{rpm}$ por $30 \mathrm{~min}$; el producto obtenido mostró una apariencia pastosa y color blanco hueso. Además se caracterizó de manera cualitativa en un espectrofotómetro UV-VIS y de forma cuantitativa en un cromatógrafo de gases (GC) (AGILENT 4890DGC) y mediante un análisis de FTIR se identificaron los diferentes grupos funcionales característicos de la dihidroxiacetona patrón (Da Silva et al, 2009) y la obtenida en la presente investigación. El rendimiento producto/ sustrato se determinó con los resultados iniciales y finales obtenidos de DHA y el consumo de glicerol por parte de la bacteria.

\section{Resultados y discusión}

\section{Cinética de crecimiento}

La cinética de crecimiento de la cepa G. oxydans se determinó por densidad óptica en un espectrofotómetro UV-VIS. Estos resultados proporcionaron el tiempo de alimentación para pasar de un proceso discontinuo a un proceso semicontinuo. En la figura 1 se aprecia cómo la curva de crecimiento de la bacteria para una concentración de glicerol de $50 \mathrm{~g} / \mathrm{l}$ se pronunció más en comparación con la curva de crecimiento para una concentración de glicerol de 100 g/l, donde la máxima concentración de biomasa que se alcanzó fue de 8.32 y $4.61 \mathrm{~g} / \mathrm{l}$, respectivamente.
En la figura 1 se observa el lapso de tiempo que duró la fase exponencial, la cual estuvo entre las primeras horas de la fermentación, para las concentraciones de glicerol de 50 y $100 \mathrm{~g} / \mathrm{l}$. La fase exponencial se presentó desde las 0 hasta las 22 h, debido a la inoculación previa, el tiempo óptimo para la alimentación se determinó entre las 12 y $15 \mathrm{~h}$ por ser la parte más pronunciada de las curvas para ambas concentraciones; por tanto, el tiempo de alimentación elegido fue de $12 \mathrm{~h}$.

\section{Cultivo fed-batch}

El cultivo fed-batch se llevó a cabo bajo las mismas condiciones del proceso batch, con alimentación continua de medio fresco rico en glicerol y el oxígeno transferido al medio de cultivo mediante una bomba de aire (Elite 802), suministrando un flujo de $25.65 \mathrm{l} / \mathrm{h}$. Se escogió un tiempo de alimentación de 12 horas, basado en la figura 1 , y tiempo de fermentación por 72 horas.

\section{Crecimiento celular y parámetros cinéticos}

En la figura 2, se observa la curva de crecimiento de biomasa para una concentración de glicerol de 50 g/l y 100 g/l. La concentración de biomasa se duplicó para la primera alimentación en $4.5 \mathrm{~g} / \mathrm{l}$ a las 12 horas de fermentación, porque hubo mayor asimilación del sustrato. Sin ambargo, disminuyó a la mitad con la segunda alimentación a $2.0 \mathrm{~g} / \mathrm{l}$. Durante las primeras $24 \mathrm{~h}$, el consumo de glicerol por parte de la cepa alcanzó $72 \%$ para una concentración inicial de glicerol de 50 g/l, y se redujo casi a la mitad (42\%) para una concentración inicial de $100 \mathrm{~g} / \mathrm{l}$; por consiguiente, a altas concentraciones de glicerol la bacteria disminuye su velocidad de consumo debido al efecto inhibitorio del sustrato (Acevedo

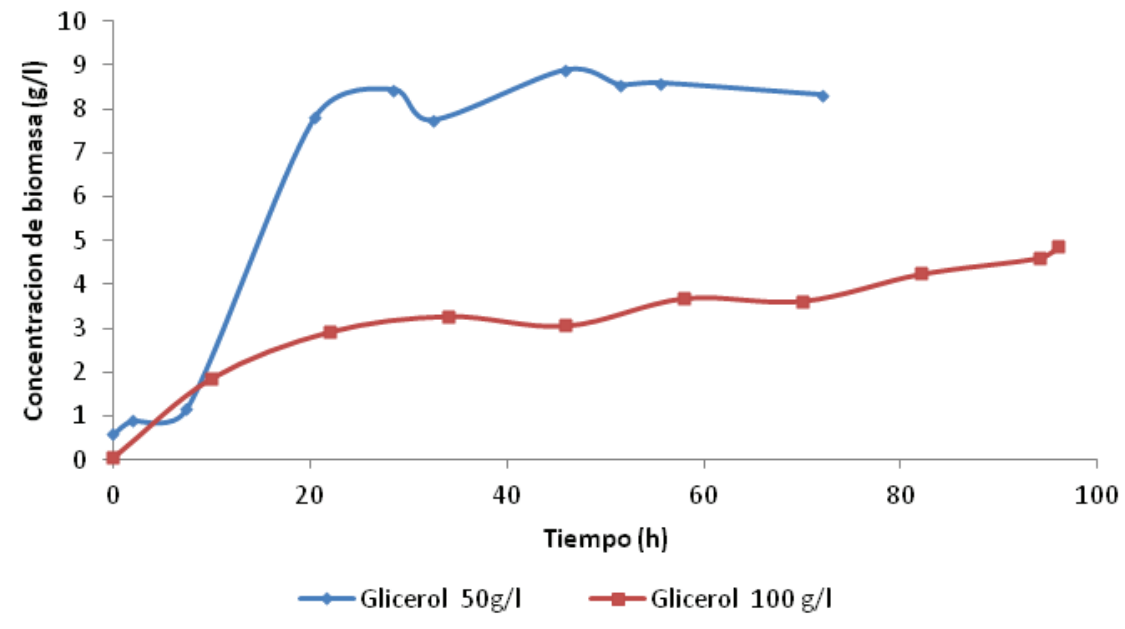

Figura 1. Curva de crecimiento de biomasa para concentraciones de $50 \mathrm{y}$ $100 \mathrm{~g} / \mathrm{l}$ de un proceso batch 


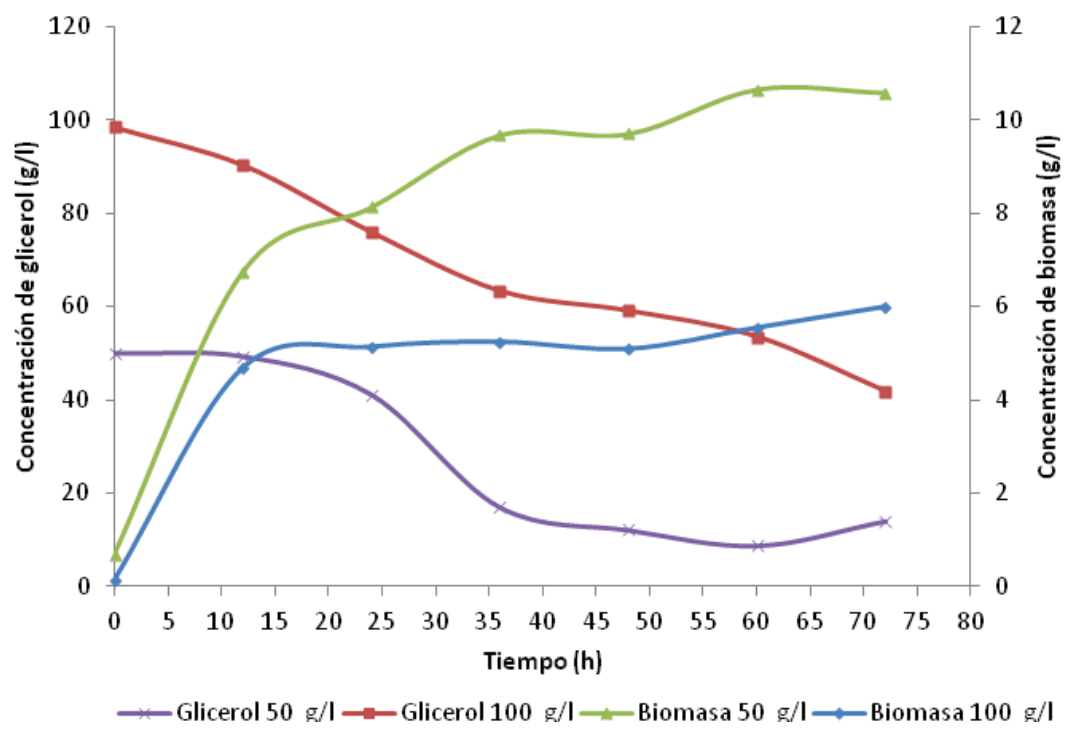

Figura 2. Crecimiento de biomasa y consumo de glicerol, para una concentración inicial de sustrato de $50 \mathrm{~g} / \mathrm{l}$ y $100 \mathrm{~g} / \mathrm{l}$ et al., 2015), ya que altas concentraciones de sustrato dificultan la permeabilidad de la membrana, lo cual limita la entrada de nutrientes (Bories et al., 1991).

\section{Concentración de DHA y rendimiento producto / sustrato}

Para comprobar que las concentraciones determinadas por el espectrofotómetro UV-VIS se consideren concentraciones reales de DHA, se analizaron las muestras en un cromatógrafo de gases (GC), lo cual confirmó la formación del producto de interés, DHA. La figura 3 muestra que la bacteria desde las primeras $12 \mathrm{~h}$ fue capaz de producir DHA con las concentraciones iniciales de glicerol de 50 y 100 g/l, obteniendo valores de 8 y $6.5 \mathrm{~g} / \mathrm{l}$, respectivamente. La generación del producto presentó altos y bajos entre las 48 y $72 \mathrm{~h}$ para ambas curvas, debido a que la alimentación del medio fresco aumentó el volumen del caldo de fermentación y la dilución de la dihidroxiacetona en el medio de cultivo. La mayor concentración de DHA alcanzó valores de 47.93 y 42.40 g/l para concentraciones iniciales de glicerol de 50 y 100 $\mathrm{g} / \mathrm{l}$, respectivamente. Asimismo, el consumo de sustrato después de transcurridas las 72 h fue de 72 y $57 \%$. Por consiguiente, la producción de DHA al igual que la concentración de biomasa fue inversamente proporcional a la concentración de sustrato, debido al desajuste entre el crecimiento y la producción de DHA, es decir, cuando las células permanecen por mucho tiempo en presencia de altas concentraciones de DHA, la células pierden la habilidad para crecer (Bories et al.,1991).

Las figuras 3 y 4 indican los métodos aplicados para la determinación de la producción de DHA y el consumo de glicerol. En la figura 3 para la concentración inicial de glicerol de $50 \mathrm{~g} / \mathrm{l}$, el sustrato disminuyó rápidamente en la primera alimentación respecto a la concentración inicial de glicerol de 100 g/l. Además, se observa que a mayor consumo de sustrato las concentraciones de DHA aumentaron de forma rápida en el transcurso de las primeras 36 horas, aunque la velocidad de formación del producto fue casi constante para ambas concentraciones de sustrato alimentado

En la figura 4 los cromatogramas de las muestras por GC tomadas a las 60 horas, para concentraciones iniciales de glicerol de 50 y $100 \mathrm{~g} / \mathrm{l}$, alcanzaron valores muy cercanos de 56.8 y 58.09 g/l de DHA, pero la conversión de glicerol a DHA se detuvo en 9.3 y $42.68 \mathrm{~g} / \mathrm{l}$ de sustrato residual, respectivamente. Por lo tanto, la concentración de DHA tuvo mayor impacto sobre el crecimiento, que sobre la formación del producto a partir de glicerol (Bories et al., 1991). Además las altas concentraciones de sustrato son inhibitorias para las funciones celulares, debido a la reducción en la actividad del agua y el aumento en la viscosidad del caldo de fermentación, que limitan el crecimiento y la actividad de la enzima glicerol deshidrogenasa (GDH) (Lijuan et al., 2010; Rock et al.,2014).

Comparando ambos métodos UV-VIS y GC para la determinación de la dihidroxiacetona, los resultados se acercaron con pequeñas diferencias en las muestras tomadas a las 48 y 72 horas. Para una concentración inicial de glicerol de $50 \mathrm{~g} / 1$ ambos métodos alcanzaron concentraciones de 45.71 y 47.58 g/l de DHA, sin embargo para una concentración inicial de glicerol de 100 $\mathrm{g} / \mathrm{l}$, las concentraciones fueron de 46.08 y $57.35 \mathrm{~g} / \mathrm{l}$, res- 


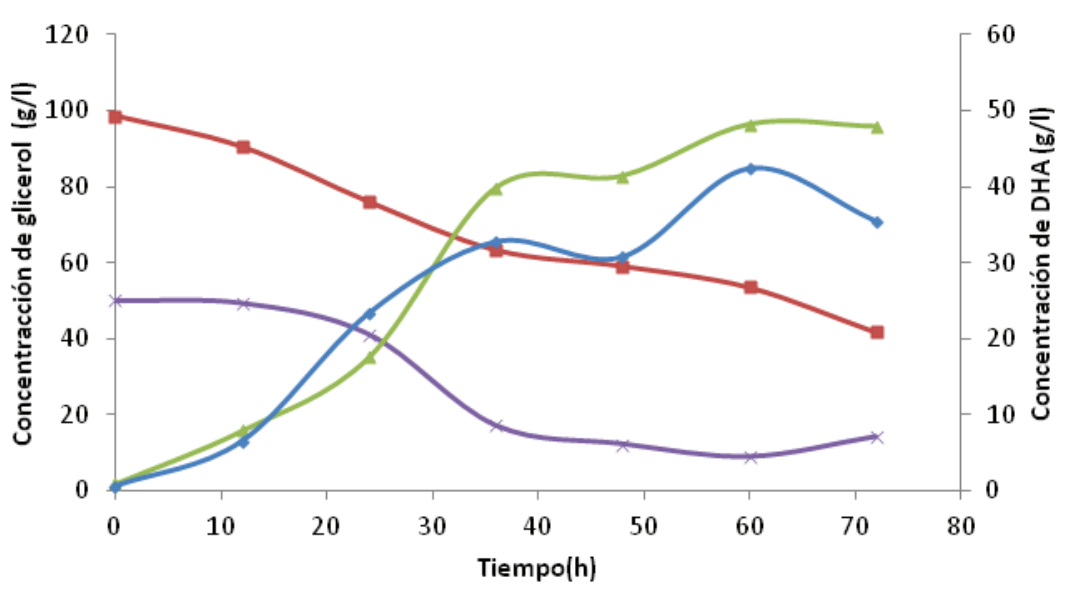

$\because$ Glicerol $50 \mathrm{~g} / \mathrm{l} \rightarrow$ Glicerol $100 \mathrm{~g} / \mathrm{l} \longrightarrow$ DHA $50 \mathrm{~g} / \mathrm{l} \longrightarrow$ DHA $100 \mathrm{~g} / \mathrm{l}$

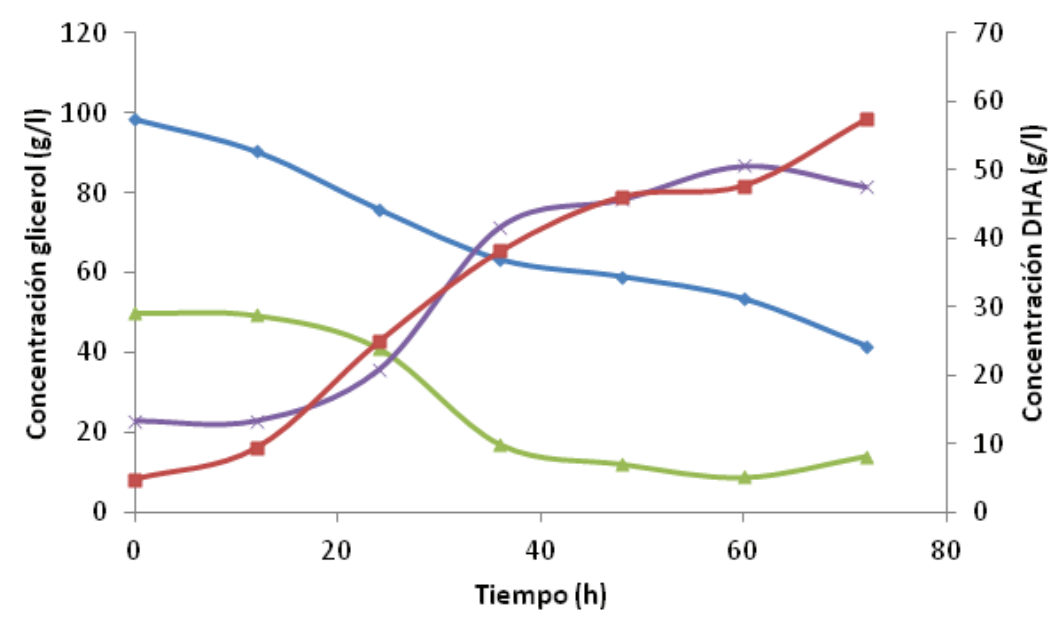

$\longrightarrow$ Glicerol $50 \mathrm{~g} / \mathrm{l} \longrightarrow$ Glicerol $100 \mathrm{~g} / \mathrm{l} \longrightarrow$ DHA $50 \mathrm{~g} / \mathrm{l} \longrightarrow$ DHA $100 \mathrm{~g} / \mathrm{l}$
Figura 3. Concentración de DHA y consumo de glicerol para una concentración inicial de glicerol de 50 y $100 \mathrm{~g} / \mathrm{l}$. UV-VIS
Figura 4. Concentración de DHA y consumo de glicerol para una concentración inicial de glicerol de 50 y $100 \mathrm{~g} / \mathrm{l}$. GC pectivamente. Los resultados obtenidos son satisfactorios, utilizando el proceso fed-batch con aireación.

En la tabla 1 se presentan los parámetros de crecimiento de biomasa y producción de DHA, calculados a partir de las curvas de crecimiento de biomasa, consumo de glicerol y producción de DHA reportados en las figuras 2, 3 y 4 . Se calcularon los parámetros cinéticos, como: velocidad específica de crecimiento, rendimiento biomasa/sustrato, velocidad de crecimiento, tiempo de duplicación, rendimiento producto/ sustrato y productividad.

Tabla 1. Parámetros cinéticos obtenidos en el proceso fed- batch

\begin{tabular}{lcc}
\hline \multicolumn{1}{c}{ Parámetros cinéticos } & $50 \mathrm{~g} / \mathrm{l}$ de glicerol inicial & $100 \mathrm{~g} / \mathrm{l} \mathrm{de}$ glicerol inicial \\
\hline$\mu_{\max }\left(\mathrm{h}^{-1}\right)$ & 0.07 & 0.10 \\
Tiempo de duplicación $(\mathrm{h})$ & 9.47 & 6.90 \\
Concentración de biomasa $(\mathrm{g} / \mathrm{l})$ & 10.58 & 5.99 \\
Concentración de DHA $(\mathrm{g} / \mathrm{l})$ & 47.58 & 59.35 \\
$\mathrm{Y} \times \mathrm{s}(\mathrm{g} / \mathrm{g})$ & 27.55 & 10.31 \\
$\mathrm{Y} \mathrm{p} / \mathrm{s}(\mathrm{g} / \mathrm{g})$ & 90.54 & 79.97 \\
Productividad de biomasa, $\mathrm{Q}_{\mathrm{x}}(\mathrm{g} / \mathrm{l} \mathrm{h})$ & 0.15 & 0.08 \\
Productividad de DHA, $\mathrm{Q}_{\mathrm{p}}(\mathrm{g} / \mathrm{h})$ & 0.66 & 0.82 \\
\hline
\end{tabular}


De la tabla 1, cuando la concentración inicial de glicerol fue de $50 \mathrm{~g} / \mathrm{l}$, hubo un aumento en el rendimiento producto/sustrato de $91 \%$, por otro lado, para una concentración alimentada de $100 \mathrm{~g} / \mathrm{l}$ fue de $80 \%$, debido a que altas concentraciones iniciales de glicerol reducen la actividad metabólica de la bacteria; por tanto, una mayor concentración de sustrato afecta el rendimiento y la velocidad de producción de DHA. Este resultado es similar a lo reportado por Claret y colaboradores, quienes emplearon diferentes concentraciones de glicerol (51$129 \mathrm{~g} / \mathrm{l})$, y obtuvieron un rendimiento producto/sustrato de $92-82 \%)$, respectivamente, debido a que el rendimiento varió de forma inversa al contenido de sustrato alimentado. Este fenómeno se atribuyó a una inhibición del crecimiento por aumento en la concentración de sustrato (Claret et al., 1992; Bauer et al., 2005). Además, altas concentraciones de glicerol (100 g/l) modifican todos los parámetros cinéticos, como la velocidad específica de crecimiento, los rendimientos y las productividades, debido a que la acción del sustrato sobre la actividad biológica no es selectiva (Bories et al., 1991). Estos resultados demuestran el efecto inhibitorio del sustrato durante el transcurso de la fermentación fed-batch. El aumento en la velocidad específica de crecimiento para una concentración de sustrato de $100 \mathrm{~g} / \mathrm{l}$, se debe a que las bacterias tuvieron menor tiempo de duplicación y crecieron con mayor facilidad por el aumento en la actividad enzimática. Claret y colaboradores (1992) indicaron que a mayores concentraciones de glicerol, la máxima velocidad de consumo de sustrato se alcanza en un menor tiempo, y luego permanece constante.

La productividad de DHA aumentó para una concentración de glicerol de $100 \mathrm{~g} / \mathrm{l}$, por la gran cantidad de sustrato disponible a degradar por parte de la bacteria logrando una velocidad específica de crecimiento mayor. Esto significó una rápida duplicación celular, pero la cantidad de biomasa fue mayor cuando se utilizó una concentración de glicerol de $50 \mathrm{~g} / \mathrm{l}$, en contraste, la fase exponencial se alcanzó a las $36 \mathrm{~h}$ para ambas concentraciones. Esto confirma la mayor productividad de $G$. oxydans en la producción de DHA aplicando otros procesos de fermentación (Bories et al., 1991; Claret et al., 1992; Hekmat et al., 2007; Lijuan et al., 2010; Zhong et al., 2011).

La tabla 1 muestra que la mejor producción de DHA se obtuvo a una concentración inicial de glicerol de 50 $\mathrm{g} / \mathrm{l}$, debido a que los parámetros cinéticos $\mu_{\max } 0.07 \mathrm{~h}{ }^{\circ} 1$; $\mathrm{Yx} / \mathrm{s}=25.55 \mathrm{~g} / \mathrm{g} ; \mathrm{Yp} / \mathrm{s}=90.54 \mathrm{~g} / \mathrm{g} ; \mathrm{Q}_{\mathrm{x}} 0.15 \mathrm{~g}$ de biomasa/ $\mathrm{lh} ; \mathrm{Q}_{\mathrm{p}} 0.66 \mathrm{~g}$ de producto/lh, son mejores para esta concentración de sustrato alimentado, por la mayor bioconversión de glicerol a DHA y el alto consumo de sustrato por parte de la bacteria.

\section{Comportamiento del $\mathrm{pH}$}

La figura 5 muestra el comportamiento del $\mathrm{pH}$ durante las 72 horas de fermentación. El pH inicial se ajustó a 5.3, pero la acidez aumentó con la producción de DHA. El pH se acidificó debido al aumento en la concentración de DHA durante las primeras $36 \mathrm{~h}$, pero después se observó que el pH se mantuvo entre 3.1 y 2.9 unidades, para 50 y 100 g/l de glicerol, respectivamente. Este comportamiento del $\mathrm{pH}$ manejando altas concentraciones de sustrato fue similar a la caída del $\mathrm{pH}$ para un proceso batch, según lo reportado por Acevedo et al. (2014), debido a que la oxidación incompleta del sustrato se favoreció con altas concentraciones de sustrato. Además, el $\mathrm{pH}$ es un parámetro importante en procesos industriales, ya que influye en el metabolismo celular y en la permeabilidad de la membrana. Hekmat et al. (2003) informaron que un $\mathrm{pH}$ bajo favorece la producción de DHA y aumenta el rendimiento producto/sustrato para la fermentación con G. oxydans.

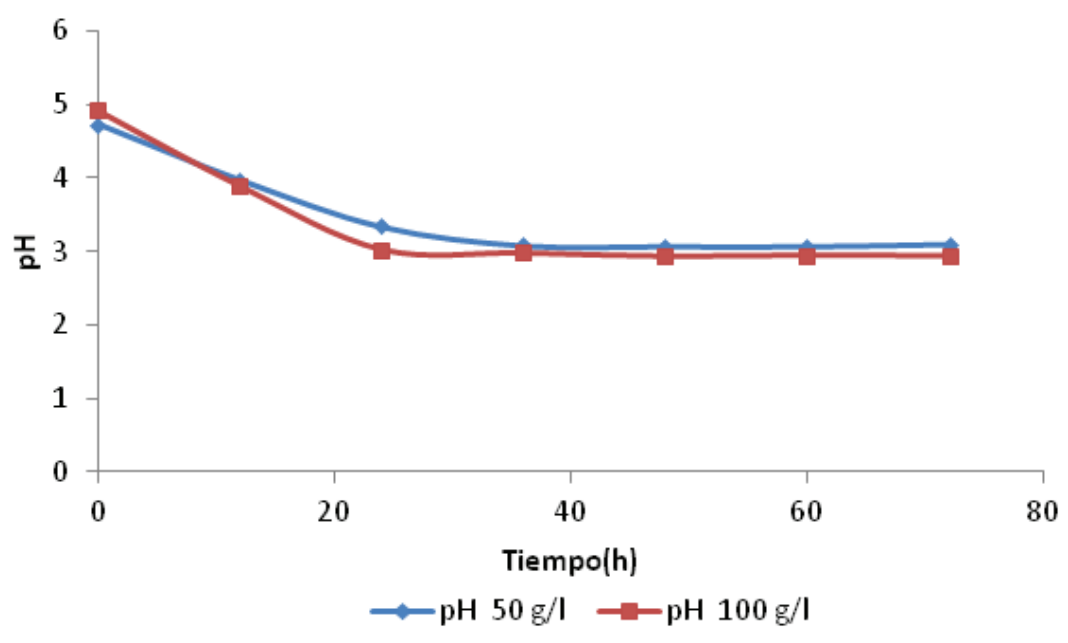

Figura 5. Comportamiento del pH para concentraciones iniciales de glicerol de 50 y $100 \mathrm{~g} / \mathrm{l}$ 
Inhibición por producto (DHA) y sustrato (glicerol)

En la figura 3 se observa que durante las primeras 60 horas, para los $50 \mathrm{~g} / \mathrm{l}$ alimentados la concentración de DHA aumentó y permaneció constante hasta terminada la fermentación. Para la segunda alimentación de $100 \mathrm{~g} / \mathrm{l}$, la producción de DHA fue menor y después disminuyó. Este comportamiento se debió a que las bacterias dejaron de producir DHA, porque parte del producto se degradó en $\mathrm{CO}_{2}$ y $\mathrm{H}_{2} \mathrm{O}$, debido a la baja concentración de biomasa en el medio, dando inicio a la fase de muerte de las bacterias en el proceso fermentativo.

Se descartó la disponibilidad de glicerol para degradarse como una explicación para la inactividad metabólica, debido a que la última alimentación de sustrato se realizó a las 60 h; por tanto, quedó glicerol disponible para seguir produciendo DHA. La razón para detener la producción de DHA fue la disminución en el número de bacterias presentes; esto se verificó en las curvas de biomasa para ambas corridas; en la figura 2 esta pausa del crecimiento bacteriano se presentó en ambos ensayos para concentraciones de DHA entre los 45 y $50 \mathrm{~g} / \mathrm{l}$ y fue provocado por la alta concentración alcanzada de DHA. A este fenómeno se le llama inhibición por producto. La inhibición se presentó debido a que el DHA juega un papel importante en el crecimiento lento de la bacteria, atribuido a la degeneración morfológica de la célula por la pérdida de estabilidad de la enzima glicerol-deshidrogenasa y al bloqueo continuo en la conversión del glicerol (Bories et al., 1991).

Se observa en las figuras 2 y 4 que el perfil de concentración para sintetizar DHA concuerda con las curvas de biomasa, este empezó a disminuir luego de las
$60 \mathrm{~h}$ de fermentación y la pendiente de la curva de concentración de DHA decayó, es decir, la velocidad de producción de DHA se limitó por la muerte de las bacterias en ese lapso de tiempo. La fase estacionaria para la curva de crecimiento de la biomasa comenzó a las $36 \mathrm{~h}$ para ambas concentraciones iniciales de glicerol, y la velocidad de crecimiento aumentó a $0.1005 \mathrm{~h}^{-1}$ para $100 \mathrm{~g} / \mathrm{l}$ en comparación con la de $50 \mathrm{~g} / \mathrm{l}$ que fue de 0.0732 $\mathrm{h}^{-1}$. La concentración de biomasa para una alimentación inicial de glicerol de $50 \mathrm{~g} / 1$ alcanzó un valor de $10.6 \mathrm{~g} / \mathrm{l}$ mientras que para $100 \mathrm{~g} / \mathrm{l}$ disminuyó a $5.98 \mathrm{~g} / \mathrm{l}$. Estos datos indicaron que a mayor concentración de glicerol se presenta el fenómeno de inhibición por sustrato.

Análisis FTIR de la muestra patrón y de la muestra obtenida de DHA

Esta prueba se hizo con el propósito de comparar no sólo el espectro de una muestra patrón de DHA y la muestra obtenida en la presente investigación, sino también la identificación y confirmación de la presencia de dihidroxiacetona. En la figura 6 se muestran los resultados arrojados por el espectrofotómetro infrarrojo FTIR, con el que se realizó la identificación de los grupos funcionales presentes en la muestra patrón de DHA y la obtenida en la presente investigación.

Al comparar la muestra patrón con la muestra obtenida se observan las bandas de frecuencia más representativas de DHA, confirmándose así su presencia. Por otro lado, el análisis reveló que en la muestra se presentaron bandas menores de sustancias ajenas a la DHA. Tales sustancias son residuos de la separación incompleta de la DHA del caldo de fermentación, posiblemente biomasa, nutrientes del medio de cultivo y etanol.

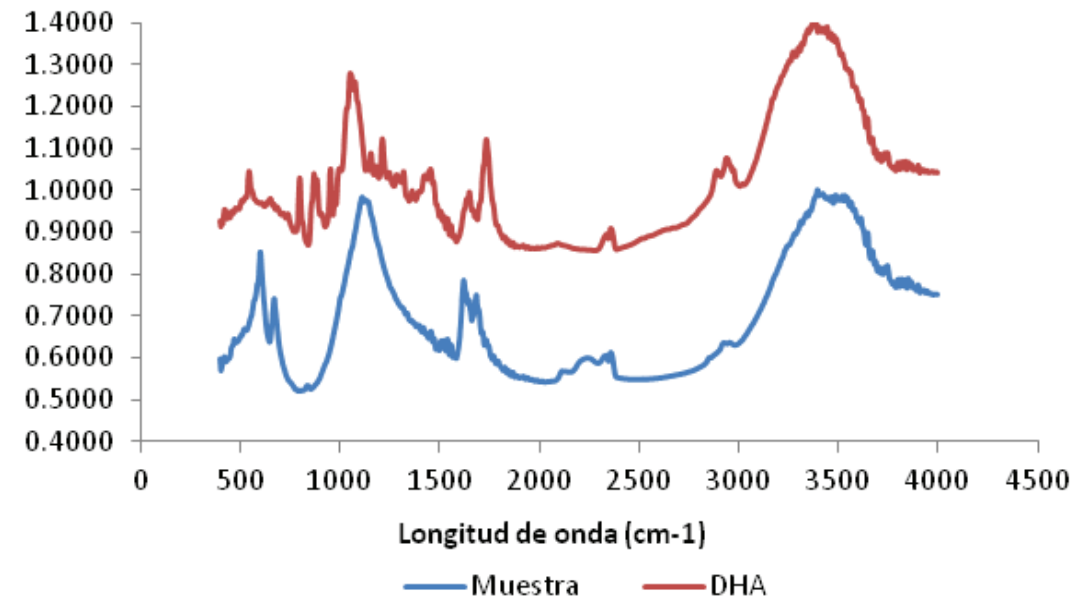

Figura 6. Análisis FTIR de absorbancia para la muestra patrón de DHA y la obtenida por el proceso fed-batch 
Comparación de parámetros cinéticos con otros estudios

Tabla 2. Parámetros cinéticos de diferentes investigaciones

\begin{tabular}{lccc}
\hline & Claret et al., 1992 & Zhong et al., 2011 & Autores \\
\hline $\begin{array}{l}\text { Tiempo de fermentación }(\mathrm{h}) \\
\text { Concentración de biomasa }(\mathrm{g} / \mathrm{l})\end{array}$ & 20 & 72 & 72 \\
Yx/s $(\mathrm{g} / \mathrm{g})$ & 1.98 & 10 & 10.58 \\
Concentración de DHA $(\mathrm{g} / \mathrm{l})$ & 3.9 & 3.11 & 27.54 \\
Y(p/s) $(\mathrm{g} / \mathrm{g})$ & 47 & 156 & 47.6 \\
Productividad de DHA $(\mathrm{g} / \mathrm{l} \mathrm{h})$ & 92 & 89.8 & 91 \\
\hline
\end{tabular}

(Claret et al., 1992) reportaron un rendimiento biomasa/ sustrato de 3.9\% para las siguientes condiciones de operación: agitación $800 \mathrm{rpm}$, temperatura $28^{\circ} \mathrm{C}$, $\mathrm{pH}$ de 6 , aireación de 1 vvm y un tiempo de fermentación 20 horas. En esta investigación se alcanzó un rendimiento de $27.54 \%$, con temperatura de $30^{\circ} \mathrm{C}, \mathrm{pH} 5.3$, tiempo de fermentación $72 \mathrm{~h}$ y la velocidad de agitación y el flujo de aire se controlaron a $150 \mathrm{rpm}$ y $1.66 \mathrm{vvm}$. Ohrem y Harald (1995) analizaron que la cantidad de oxigeno consumido por la bacteria es directamente proporcional a la tasa de oxidación de glicerol y a la velocidad de formación de producto. Por tanto, a mayor producción de biomasa mayor será el rendimiento biomasa/sustrato. El aumento en el rendimiento, se atribuyó al modo de operación fed-batch, el cual tuvo mayor flujo de aireación y tiempo de fermentación (tabla 2).

Zhong et al. (2011) reportaron un rendimiento biomasa/sustrato de $3.11 \%$, con las siguientes condiciones de fermentación: agitación $400 \mathrm{rpm}$, temperatura $30^{\circ} \mathrm{C}$, $\mathrm{pH} 5$, aireación de $1.5 \mathrm{vvm}$ y $72 \mathrm{~h}$ de fermentación alcanzando un rendimiento biomasa/sustrato de $24.44 \%$, aunque las condiciones en las que se realizó la fermentación fueron muy parecidas, exceptuando la agitación que fue casi el triple de la manejada en el proceso fedbatch. La disminución en el rendimiento se debió a la presencia de glicerol disponible para la degradación y la baja concentración de biomasa alcanzada en el proceso fermentativo. Como resultado alcanzaron una concentración de DHA de 156 g/l, a una concentración inicial de glicerol de $180 \mathrm{~g} / \mathrm{l}$ y un rendimiento producto/ sustrato de $89.8 \%$, solo $1.2 \%$ por debajo del obtenido en la presente investigación (tabla 2).

Bories et al. (1991) y Lijuan et al. (2010) manejaron condiciones experimentales idénticas respecto al pH 6 y temperatura de $28^{\circ} \mathrm{C}$, pero variaron agitación y aireación a $800 \mathrm{rpm}$ y $1 \mathrm{vvm} ; 500 \mathrm{rpm}$ y $6 \mathrm{vvm}$ para una cepa mutante, respectivamente. Existe mayor conver- sión del glicerol a DHA cuando se aumenta la cantidad de oxígeno disuelto en el medio de cultivo, lo cual favoreció las necesidades de oxígeno de la bacteria. El rendimiento producto/sustrato que se logró en la investigación fue de $91 \%$, el cual coincide con Lijuan y colaboradores (2010).

Aunque la cantidad de DHA producida se determinó por cromatografía de gases, su productividad fue baja comparada con los resultados reportados por (Claret et al., 1992; Zhong et al., 2011), el rendimiento biomasa/sustrato y producto/sustrato se mejoró, debido a los factores físico-químicos utilizados: medio de cultivo, aireación, $\mathrm{pH}$, agitación y temperatura que favorecieron el crecimiento de la célula y la síntesis de producto.

\section{Conclusiones}

El glicerol es un sustrato adecuado y económico para la producción microbiana de DHA en fermentación con G. oxydans. Se determinó que para la síntesis de DHA es necesario mantener un $\mathrm{pH}$ ácido, ya que la mejor producción se dio a $\mathrm{pH} 3$ con un rendimiento producto/ sustrato de $91 \%$. La producción de DHA a partir de glicerol, depende del flujo de aireación, el tiempo de fermentación y las condiciones de operación. Se seleccionó una alimentación de $50 \mathrm{~g} / \mathrm{l}$ para mayor aprovechamiento del sustrato con una concentración de DHA de 47.58 $\mathrm{g} / \mathrm{l}$, un rendimiento de 27.54 gramos de DHA por gramo de glicerol consumido, un rendimiento de $91 \%$, una agitación de $150 \mathrm{rpm}$ a temperatura de $30^{\circ} \mathrm{C}$ y $\mathrm{pH}$ de 5.3. Con una baja alimentación de glicerol se evita el efecto inhibitorio por sustrato. Se observó que un aumento en la aireación permite incrementar la producción de DHA y mejora la estabilidad del proceso fed-batch. Estos resultados muestran que es viable la producción de DHA a partir de glicerol a un bajo costo. Por lo tanto, es posible solucionar los problemas de 
acumulación y contaminación del glicerol como subproducto de la síntesis del biodiesel.

\section{Agradecimientos}

A la Universidad de Cartagena, Laboratorio de Biotecnología del programa de Ingeniería Química, Laboratorios de Ingeniería de alimentos y Química y Farmacia, que permitieron la realización de este proyecto con resultados satisfactorios.

\section{Referencias}

Acevedo M., De Avila G., Realpe A. Assessment of pH Change in Dihydroxyacetone Production from Glycerol. International Journal of Applied Engineering Research, volumen 9 (número 24), 2014: 29239- 29246.

Acevedo M., De Avila G., Realpe A. Microbial conversion of glycerol to dihydroxyacetone by using batch mode. International Journal of Applied Engineering Research, volumen 10 (número 6), 2015: 14615-14620.

Bauer R., Katsikis N., Vargas S., Hekmat D. Study of inhibitory effect of dihydroxyacetone Gluconobacter oxydans product in a two stage semi-continuous fed batch process repeated. Bioprocess Biosyst. Eng., volumen 5, 2005: 37-43.

Bendeck J. Biocombustibles alternativa energética presente y futuro de los biocombustibles en Colombia, Federación Nacional de Biocombustibles, 2010.

Bories A., Claret C., Soucaille P. Kinetic study and optimization of the production of dihydroxyacetone from glycerol using Gluconobacter oxydans. Proc. Biochem. volumen 26, 1991: 243-248.

Canales F., Garza C., Moreira H., Acevedo J.A., Torre O.J., Montaño C., Marroquín S. Prospectiva de petrolíferos energéticos 20052014, Secretaria de Energía (SENER), México, 2006.

Cárdenas D., Pulido C., Aragón O., Ancízar F. Evaluación de la producción de 1,3-propanodiol por cepas nativas de Clostridiumsp. Revista Colombiana Ciencias Químicas Farmaceúticas, volumen 35 (número 1), 2006: 120-137.

Cardeño F., Gallego L.J., Ríos L.A. Refinación de la fase glicerina del biodiesel de aceite de palma usando ácidos minerales. InformaciónTecnológica, volumen 22 (número 6), 2011: 15-24.

Claret C., Bories A., Soucaille P. Glycerol inhibition of growth and dihydroxyacetone production by gluconobacteroxydans. $\mathrm{Cu}$ rrent Microbiology, volumen 25, 149-155: 1992.
Gupta A., Singh V., Qazi G., Kumar A. Gluconobacter oxydans: Its Biotechnological Applications. Microbiol Biotechnol, volumen 3, 2001: 445-456.

Hancock H. Biodiesel overview on global production and policy, trade and development, Department of Agriculture Western Australia, 2005.

Hederich D. Los biocombustibles en Colombia y el mundo, corporación para el desarrollo industrial de la biotecnología y producción limpia, 2010.

Hekmat D., Bauer R., Fricke J. Optimization of the microbial synthesis of dihydroxyacetone from glycerol from Gluconobacter oxydans. Bioprocess BiosystEng., volumen 26, 2003: 109-116.

Hekmat D., Bauer R., Neff. V. Optimization of the microbial synthesis of dihydroxyacetone in a semi-continuous repeated-fed-batch process by in situ immobilization of Gluconobacter oxydans. Process Biochemistry, volumen 42, 2007: 71-76.

Lijuan M., Wenyu L., Zhendong X., Jianping W. Enhancement of dihydroxyacetone production by a mutant of Gluconobacter oxydans. Biochemical Engineering Journal, volumen 49, 2010: 61-67.

Ming-hua L., Jian W., Xu L., Jin-ping L., Dong-zhi W., Hao C. Enhanced production of dihydroxyacetone from glycerol by overexpression of glycerol dehydrogenase in an alcohol dehydrogenase-deficient mutant of Gluconobacter oxydans. Bioresource Technology, volumen 101, 2010: 8294-8299.

Ohrem H. y Harald V. Process model of the oxidation of glycerol with Gluconobacter oxydans. Process Biochemistry, volumen 31 (número 3), 1995: 295-301.

Priscilla F., Fonseca A., Felix T., Cardoso G. Glycerol valorization: New biotechnological routes. Food and Bioproducts Processing, volumen 87, 2009: 333.

Rock J.M., Acosta A., Berenguer J., GuisanJ M., Lopez-Gallego F. Selective oxidation of glycerol to 1,3-dihydroxyacetone by glycerol dehydrogenase immobilized covalently with greater stability and reduced product inhibition. Bioresourse Technology, volumen 170, 2014: 445-453.

Silva P., Da Mack M., Contiero J. Glycerol: A promising and abundant carbon source for industrial microbiology. Biotechnology Advances, volumen 27, 2009: 30-39.

Zhong-Ce, H., Yu-Guo Z., Yin-Chu S. Use of glycerol for producing 1,3-dihydroxyacetone by Gluconobacter oxydans in an airlift bioreactor. Bioresource Technology, volumen 102, 2011: 7177-7182.

Zhu S., Qiu Y., Zhu Y., Hao S., Zheng H., Li Y. Hydrogenolysis of glycerol to 1,3-propanediol over bifunctional catalysts containing Pt and heteropolyacids. Catalysis Today, volumen 212, 2013: 120-126. 


\section{Semblanzas de los autores}

Gezira De Avila-Montiel. Docente asistente en el programa de ingeniería química de la Universidad de Cartagena, Colombia. MSc. en ingeniería química de la Universidad Nacional de Colombia, Sede Bogotá, Colombia. Ingeniera química por la Universidad de Antioquia, Medellín, Colombia. Sus áreas de investigación se centran en biomateriales modificados con nanopartículas para aplicaciones antimicrobiana y antifúngica; aprovechamiento de biomasas y residuos agroindustriales; biopolímeros para remoción de contaminantes y obtención de biocombustibles.

Álvaro Realpe-Jiménez. Director y docente asistente del programa de ingeniería química de la Universidad de Cartagena, Cartagena, Colombia. Ingeniero químico por la Universidad del Atlántico, Barranquilla, Colombia, 1998. En 2002 obtuvo el grado de M.Sc en ingeniería química por la Universidad de Puerto Rico. En 2007 obtuvo el grado de Ph.D. en ingeniería química por la Universidad de Puerto Rico. Sus áreas de investigación incluyen membranas poliméricas para celdas de combustible, energías renovables, modelación de procesos industriales y tecnología de partículas.

Jhon Edward Duran-Ariza. Ingeniero Químico orientado a la ingeniería de procesos y producción con experiencia en industria de fertilizantes Industriales, control de procesos en tratamiento de aguas, así como labores QA/QC en manufactura de guantes de vinilo. Actualmente labora como Ingeniero de servicios técnicos para equipos de cromatografía de alta gama. Desarrolló su tesis en investigación para aprovechamiento del Glicerol, logros curriculares como elaboración de proyectos de tratamiento de agua.

María Teresa Acevedo-Morantes. Docente asistente del programa de ingeniería química de la Universidad de Cartagena, Colombia. Ingeniera química por la Universidad Industrial de Santander, Bucaramanga, Colombia, en 1999. En 2005 obtuvo su M.Sc. como ingeniera química en la Universidad de Puerto Rico. Sus áreas de investigación se orientan a membranas poliméricas para procesos electrolíticos, separación de dióxido de carbono y celdas de combustible. Además, ha desarrollado otras investigaciones con aplicaciones médicas como encapsulamiento de drogas médicas y síntesis de polianhídridos para tratamiento de cáncer.

Heidy Yaneth Bonfante-Álvarez. Ingeniera química de la Universidad de Cartagena, año 2013. Participó como joven investigadora de COLCIENCIAS durante el periodo 2013-2014. Sus áreas de investigación se orientan en la obtención de productos biotecnológicos y en biomateriales para la adsorción de metales pesados. 
DOI: https://doi.org/1 0.1016/j.riit.2016.07.004 